\title{
Education to Theatricality inside Secondary School, Art and Body
}

\author{
Gaetano Oliva \\ Italian Department, Faculty of Education, Catholic University, Milan, Italy \\ Email: gaetano.oliva@unicatt.it
}

Received 1 September 2014; revised 30 September 2014; accepted 15 October 2014

Copyright (C) 2014 by author and Scientific Research Publishing Inc.

This work is licensed under the Creative Commons Attribution International License (CC BY). http://creativecommons.org/licenses/by/4.0/

(c) (i) Open Access

\section{Abstract}

The aim of this study was to present results of Education to Theatricality (IT: Educazione alla Teatralità) as scientific research and innovative pedagogy in the sector of the education of the person. Education to Theatricality has a lot of purposes to contribute to the psycho-physic well-being of each person; particularly it wants to help everyone to realize himself, as human being and as social actor; it wants to give everybody the chance to reveal his own diversity and specificity, because everybody has a message to convey through his body and his voice. The Education to Theatricality wants to stimulate skills, it wants to develop a better awareness of interpersonal relationships; it wants also give space to the assignment meaning process, because it considers "doing" as important as thinking, which permits to develop awareness about personal acts. Education to Theatricality is a science that includes pedagogy, sociology, human sciences, psychology and performative art in general. The scientific nature of this discipline allows to apply it to the most part of the contexts and of the persons, because it has in the centre of its pedagogical process the human being, as such he is and not necessarily with any skill. The training of the actor-person is one of the most important principles of the Education to Theatricality: the most important purpose is the development of the creativity and the imagination through a work, based on scientific principles that the actor-person leads on himself. The ultimate aim of this science is not to transform the human in an actor-object, shaping him just for packed shows that can be easily sold, but to allow him to enhance his own qualities respecting his personality. The theatrical activity in the school and in the educational centers for children teenagers stimulates and protects the inventive skills of the students.

\section{Keywords}

Innovative Pedagogical Models, Art Education, Aesthetic Education, Early Childhood Education, Special Education, Theatre Education 


\section{Introduction: The Relationship between School and Theater}

Students, in particular the students of secondary school, have always been interested into and dramatic art. In fact, theater attracts them and stimulates their fantasy, satisfies their curiosity and their love for movement; in fact, actions and dialogues are the essence of most of their amusements.

The success of dramatic art in the scholastic area was actually quite new and it arose with the gradual change of the training perspectives of teenagers. Over the past few years, pedagogy, inspired from psychology, medicine and existential philosophy, has corrected his intellectualism and started to underline the importance to have a vision of the whole human being, who is composed by different components. At the same time, it emphasizes the inventive possibilities of each person. The dramatic expression, as a mean of education, is the perfect answer to this new cultural perspective.

In fact, it can be considered for every student like a liberating mean as well as the play. But, respect play, theatre is richer of contents and it implies a higher level of personal and emotional involvement encouraging cognitive and affective growth. This kind of dramatic art does not aspire to become a finished artistic expression and it does not intend to provoke admiration or criticism. The result of the process carried out by the student is important because it is the expression of his maturity. It is the possibility for every student to put himself on test, establishing new relationships with themselves and with the rest of the world. Dramatic expression, in fact, is a constant call for every kind of language. Spontaneity is not lawlessness or disorder, in fact it is necessary to adapt roles and to build agreements with others to increase our own ego and to tend to a greater awareness. The theatrical activity therefore does not claim any immediate scholastic result, but it stimulates and protects the inventive skills of the students.

\section{The Language of Body}

It is crucial to emphasize the role of gesture in the dramatic expression because it allows every teenager to "feel” his own body as something important in the mechanism of relationships. Today semiology and linguistics consider verbal and nonverbal communication as the most important human means of communication so it is important to understand how a teenager uses body language. First of all we have to clarify if we can define a "language” the teenager's storytelling. Actions are organized in precise movements: climb up and down, run, roll out different object, climb chairs or furniture. Dramatize a situation means play it with the body, so other people ca understand the meaning. Gesticulation appears as an expressive function that develops during childhood.

A teenager has internalized situation and he will translate it voluntarily into the body language, making conscious, intentional and annotative gestures, which will be understandable to the others. These gestures cannot always be recognized by everybody because they are polysemous, that is interpretable in different ways; therefore, sometimes, the action is supplemented by verbal language, which completes it and makes disappear any ambiguity.

On the other hand, the presence of the group and sentences like "we did not understand" push the teenager to change his gestures, to make them more meaningful and more understandable. The attitude of the players is revealed as discovery and exploration of behaviors, as a manifestation of a psychological mobilization that engages the whole being of intentionality oriented toward others. It happens for example, when teenagers have to work in pairs, to act and react in function of another person, and even in function of the group of non-participants, which constitutes an active public. We can talk about nonverbal communication when a teenager intellectualizes his actions that mean giving them a sense creating a code in such a way that these same actions are perceived and understood by the group. Linguistic define this fact as the evolution of natural gesture in cultural gesture. The expression through movement transforms the participant into the coder sender and the not participant (the receiver) into the decoder.

We have to underline even the poverty of gestural language, due to the fact that the code of gestural communication does not allow creating concepts. We have to admit that gestural creations are efficient, if carried out in the manner described above, because, through them, a subject makes himself understandable, and above all he is fulfilled realized. He transforms himself using the gestural language that is discovered through and into dramatic storytelling.

We can define this behavior as a communicative behavior, which goes beyond a simple practical or utilitarian behavior. The latter allows the teenager to establish efficient relationships with the object; the dramatic storytelling is virtual, it develops and start from a symbolic level, being based on representation. We have not intention to value mental or bodily aspects of storytelling, but we can underline that they support and complement each 
other. There are numerous accurate data that demonstrate how this kind of experience has helped many young people who have difficulties at a motor level as well as at a language level. We can mention the example of so many foreign students attending Italian schools. Throughout the long adjustment period of these guys in the life of the class, the nonverbal communication is one of the activities that allow them to participate in group activities. Dance and mime, in fact, offer everyone a chance of expression and also of communication. So they can establish the first actual and important relationships with schoolmates.

There is not the embarrassment of verbal communication and everybody can have the chance to live situations in which feeling integrated and participant. They understand these situations and create a link between them and some elements of the speech. Even if they are not perceived in their linguistic sense they are detected as one of the elements of communication. It can be said that the step of gestural language experienced into the dramatic storytelling is a first attempt of communication and it is especially an active production, which liberate vital energies of the human being.

\section{Movement or Dance?}

Movement has always been a part of human's life: from an anthropological point of view, there is a primary and existential relationship between human beings and movement. We can see that even from the simple biological point of view: our organism is in constant motion, in fact, each person is subjected to a series of stimuli and impulses in every moment time of their life. Therefore every human being is inserted in a continuous rhythm, starting from his conception to his death. So it can be said that immobility is not part of human being, and that the motion is something tightly linked to life, which assumes a central role in the relationship with oneself and with others. Man always creates a relationship through movement: "I meet the other through the movement of my body", that can be manifested through a handshake, a hug, a look, or through lulling or calling somebody by name.

In an ancient Chinese book we can read: "A man pronounced words in joy. Those words are not sufficient, so he prolongs them. The prolonged words are not enough, so he modules them. The modulated words are not sufficient, yet; without realizing it, his hands make gestures and his feet shake...” (Testa, 2005: p. 9).

In particular, dance is an artistic expression characterized by movement. Dance and movement, in fact, are an active, bodily, expressive and communicative mean. Dance has always been part of human life: it was part of primitives society, such as a collective participation in the group events; "[...] it was used to celebrate, for example, births, weddings, harvest time and wars” (Payne, 1997: p. 13). In these societies was a habit to create gestures and movements based on rhythm of heart: dance was intended to create a precise rhythmic order of movements with the aim to organize and put in order universe. The purpose was to establish a harmony between earth and sky, so men could try to create a relationship with the Divine. The body, therefore, had to get rid of all its limits to open up a free dance, without constraints, to be able to enter the spiritual dimension; so, men could reach soul trough the body.

History of dance is an amazing cultural, aesthetic, social and anthropological adventure, and it should be considered part of history of Man. They are linked together, especially if we consider it as body language, the first expressive mean that human being owns since birth and with whom every man identified himself. Dance responding to an universal irrepressible impulse to movement (Guatterini, 2008: p. 9).

But throughout history of man, dance takes on another meaning: since the seventeenth century, it started to be codified in styles and strict rules determining an academic specific language. So the art of dance was no more considered a social phenomenon. A new vision of dance appeared and it was based on training and on the discipline of the body. So, dance loses its most creative and deeply expressive characteristic.

To analyze the Creative Movement we must necessarily regain the anthropological view of primitive dance: for this reason it is more appropriate to talk about movement instead of dance, because we have to bring back the look on that specific and natural feature of man, which is the one strictly linked to the movement.

So, movement cannot be considered part of just one particular artistic discipline, but it must be inserted into a wide-ranging analysis of man and of human being's existence. Movement crosses several disciplines because we start our synthesis from the anthropological concept of art, which does not coincide with the realization of an aesthetic product, but with man's need to manifest and represent himself. Expressive arts become a vehicle through which every man finds and defines his own place in the world. Art is linked to a process, an inner research of meaning carried out by the person; it is tied to the universal Ego of human nature.

Through movement man expresses what words can not pronounce; the body is the bearer of a silent message 
that words alone cannot communicate. The overflow of vitality or the tumult of feelings have forced men to find a tool to express themselves, and they have found this tool in their body, which is the most direct instrument that every man has at his disposal. To be able to express our feeling through our body is really wonderful, it sounds quite like a miracle (Testa, 2005: p. 9).

Any human activity is characterized by expressive elements. Every phase of movement and every gesture reveal an aspect of human being and of personality; this is the actual characteristic that distinguishes man from animals. The movements of the latter are instinctive and corresponding to specific external stimuli, while the movements of human being are charged with significance because they communicate and express their inner condition.

It can be seen as the finality of human movement coincides with the aim of the twentieth century innovative theater. They both are developed through the discovery of the body and the relationship of the individual with his Ego and with others people within the context of his life. With the birth of this new form of theater, the figure of the person-actor blossoms: he is a man in search of his Ego and his expression. He is the "artist of spontaneous, gestural, emotive and vocal action, he is master of his own creativity, which springs from a great inner force, he is bearer of authentic values in which a spectator can see himself” (Oliva, 2005: p. 231).

Since this moment, theater becomes the place of discovery and possibility where you have the chance to put yourself on the line, in which creativity can be expressed freely, without any constraint.

Inevitably, this has led to the encounter between theater and education; in particular, Jerzy Grotowski fully realizes this encounter in fact he plans and creates the theater laboratory, a place in which you accept to express and show yourself.

Grotowski talks about a kind of art that has become a vehicle of something greater than the theater itself; it is no longer the actor that builds theater, but it is theatre that becomes a tool of knowledge for the actor as a man, as a person. The laboratory aims to discover the man who exists beyond the actor, looking for the origin of his action and his creativity, even if it remains a place where you work to build a representation (Oliva, 2005: p. 233).

Experimentation and exploration, comparison and confrontation with themselves and other realities acquire meaning and value, "so we can enter inside theatre with our whole Ego, starting from this practical work that is actual realized” (Oliva, 2005: p. 233).

Theater becomes a tool that allows to discover the inner part of a person and to know his relationship with others. Thanks to this intermediary position, theater allows every person to collect and check the different situations that he or she has to tackle, so he or she can internalize them and use them to express his or her own personal reality. This work, in addition to requiring a great participation and willingness by the subject, considers man in his entirity: body, soul and intellect are interdependent and there is a continuous dialogue among them; the body is enhanced and becomes a very important expressive instrument; relationship is the basic modality of the process, both at an individual and at a group level. The external environment in which the person is inserted becomes another key point of the investigations; the theater workshop is chosen as the most important methodological tool to allow the developing of this process through the promotion of a deeper awareness and a consciousness.

In this struggle with one's own truth, this effort to peel of the life-mask, the theatre, with its full-fleshed perceptivity, has always seemed to me a place of provocation. It is capable of challenging itself and its audience by violating accepted stereotypes of vision, feeling and judgment-more jarring because it is imaged in the human organism's breath, body, and inner impulses. This defiance of taboo, this transgression, provides the shock which rips off the mask, enabling us to give ourselves nakedly to something which is impossible to define but which contains Eros and Caritas (Grotowski, 1970: p. 28).

So theatre becomes a pedagogical and educational instrument and in this encounter Education to Theatricality finds its origin. Thanks to the contribution of important figures in pedagogical field, including in particular Maria Montessori and John Dewey, theater becomes a language which can be used to educate and to be educated; "The theater is an efficient mean of education because it involves the whole human being, his deep humanity, his awareness of values, his most immediate and spontaneous socialization” (Oliva, 2005: p. 234).

\section{Education to Theatricality}

\subsection{Theatricality: Expressive Arts and Pedagogy}

Thanks to the laboratory model created and developed by Grotowski, a new form of theatre begins. Its aim is to 
educate the person. It is a warm and friendly environment in which man is able to enhance his psycho-physical well-being through a process that leads him to experience both his own intimacy and external reality, without fear to be judged, because the starting point is the respect of the experimentation, of creativity and of personality of the other. So, "theater does not promise to transform a man in a super-man, but it can be an excellent test, can give to everyone the measure of his personal nature. So we do not talk about an actor as an abstract entity, but of a 'person-actor' [...]" (Oliva, 1999: p. 93). Grotowski's Laboratory is based on the concept of person-actor, whose finality is precisely to value and respect personal qualities; the idea of object-actor is denied: the man is no more seen as an object of the market because which is considered only as an executor of an artistic product.

The main difference between these two visions is that in the first, the show takes on a value relative to the training process of the performance itself; the product has an importance because it is the fruit of creativity sprung from the relationship of individuals during the laboratory. In the second case, instead, the artistic production has a value in itself and it is the objective to achieve.

The starting point, therefore, is to keep that natural expression that every one retains within himself; you can define it pre-expressivity, a term that is derived by Eugenio Barba's Theater Anthropology (director and Italian theatre theorist, as well as a student of Grotowski), which "studies the human behavior at a biological and sociocultural level in a situation of representation” (Oliva, 1999: p. 90).

In the construction of the person-actor, the purpose is just to develop the person in its organic structure, starting from his or her nature and essence, through a work on the Ego that will allow this person to reach his or her natural, physical, emotional and intellectual pre-expressivity. The spontaneity that man manifests through these components will be addressed towards theatrical methodology so as to develop individual creativity. Man is a relational being, therefore it is necessary that he carries out this individual process within a group. The encounter and the comparison with other people allow him to enter in a dimension of greater understanding of himself and of the others. In fact, thanks to the verbal and nonverbal responses to the behavior of others, the man increases his knowledge and it is placed in a state of discovery. In addition, this situation helps him to be sensitive about the management of space and time. In summary, pupils are accompanied in the conquest of their I-AM.

"It was necessary to educate the man and not just the actor, accompanying him to develop a strong selfawareness through a process of discovery and knowledge that began, first of all, from the internal resources of the person. The advice was to always start [...] from themselves to established, with the partner, authentic and sincere relationships” (Oliva, 2005: p. 232).

So we confirm, once again, the convergence between art and education: the relational aspect, in fact, turns out to be a key factor both in the educational relationship as in artistic-theatrical relationship. Like education, the theater is a place of encounter: the exchange that takes place between the participants opens the door to so many possibility of discovery. It is not possible, in fact, that an individual may walk on the same path of someone else, because the process in which he is inserted is purely personal because we find ourselves faced to a modality of education that involves the human being in his complexity and in his natural expressiveness.

It is possible to summarize this idea with the Figure 1.

Moreover, there is another type of relationship in addition to the relation with our Ego, with a partner and with the context: it is the continuous dialogue that has always to exist between the artistic discipline and other sciences.

In particular, theater has to communicate: with pedagogy, the educational science par excellence that investigates the person as an educable human being and that bases the educational action on relationship; with sociology as a science that studies man in relation to the society in which he is inserted, investigating its influences and characteristics; anthropology, because it is a science that studies the human being in his essence and from different points of view (social, cultural, religious, philosophical, artistic-expressive); philosophy as science that raises questions about man and reflects about sense of life; aesthetics, field of philosophy that explores the relationship between human being and beauty by an artistic, scientific, moral and spiritual point of view; psychology as a science that studies the behavior of man under the psychic/mental profile and, last but not least, all disciplines of expressive arts. Thanks to this interconnected dialogue, every man is considered in his whole being.

\subsection{Education to Theatricality and Creative Movement}

Education to Theatricality reveals many different aims to contribute to the psycho-physical and social wellness of every person; in particular it wants to help each person to realize her or himself as an individual and as a so- 


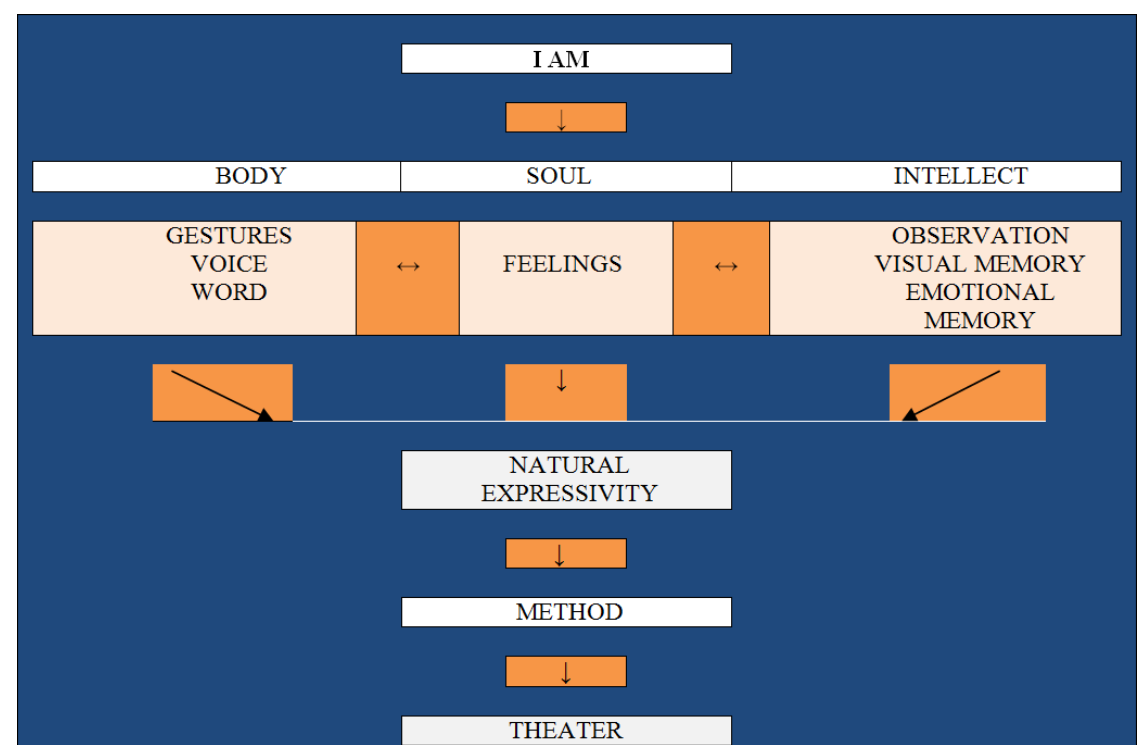

Figure 1. I-AM’s scheme. Source: Oliva, 1999: p. 98.

cial subject; it wants to give the opportunity to everyone to express their specificity and diversity, as a bearer of a message which should be communicated through body and voice; it wants to stimulate skills; it wants to build a greater awareness of interpersonal relationships; it wants to give space to the process of signification assignment, because it considers action as well as reflection, which allow persons to gain awareness of their actions.

\subsection{The Laboratory}

A fundamental aspect of the laboratory of Education to Theatricality is the personal relationship between the participants; a similar relationship should exist between actors and spectators during the creative project that concludes the laboratory itself. The openness to the other is a feature that deeply belongs to man; it is not just a simple exchange of communication, but an experience of affective participation and reciprocity. However, the desire to encounter the other should be real and authentic: this implies that everyone accepts others as they are. The laboratory therefore is an opportunity to grow, to learn by doing, with the belief that the most important thing is the process and not the product: the performance (or creative project) is just the conclusion of a training program. The theatrical activity stimulates the need of an interpersonal knowledge that leads to a relationship in which others are recognized in their dignity. The laboratory offers the opportunity to understand that it is possible to change certain situations and to change ourselves. The laboratory of Education to Theatricality has a great pedagogical value and offers an important contribution to the educational process, because, thanks to the personal training, everyone can learn to express what it is "screaming” inside, to understand and control our energy, to accept what at first was suppressed or repressed. We should not forget that personality of man depends on the quality of his experiences, which characterize his way of relating or not relating, that is his lifestyle. Theater and in particular the laboratory, allows to make new experiences and to experiment different and unusual life situations, which can contribute to redefine the Ego but even the world and the others. Theater means also see again our past: re-experience fears, relive certain behavior-or situations, not to remove them, but to realize that now we are stronger and we can recognize our positivity.

\subsection{Aesthetic}

In this context, theater becomes a sort of exercise of beauty, that allows us consider reality in a different and unusual way helping us to find something beautiful everywhere. Interpret reality using the idea of beauty as a key, allow us to abandon the repetitiveness of experience that inhibits every change and helps to understand the complexity of reality which is made of beautiful and ugly things. Theater can therefore be considered as education to beauty, as the acquisition of a new instrument of judgment, as an important chance of socialization, as an instrument of change, as a cathartic representation that allows us to think that there is beauty in every human en- 
counter, in every interaction, in any environment.

\subsection{Art as a Vehicle}

Education to Theatricality, which find its psycho-pedagogical basis in the concept of art as a vehicle defined by Grotowski, is education for creativity and it represents a precious opportunity for anyone to affirm their identity, claiming the value of the expressive arts as a vehicle for overcoming the differences and as an actual element of integration.

Through art, man can tell something about himself, and he is the protagonist of this creation. It puts him in touch with himself, but, at the same time, it creates a connection with the space in a temporal dimension. The Education to Theatricality is a vehicle of growth, of individual development, of self-assertion and of acquisition of new personal skills. The expressive arts do not present models, in fact every man should be each his own model. So, the identity of every person creates a relation through a telling reality; action, word and gesture become instruments of investigation of life. Performance art becomes a vehicle for self-knowledge, for the manifestation of his own creativity.

Art as a vehicle "generates" the idea of an person-actor defined performer, an actual man of action, because he is dancer, musician, actor, total man, which performs a performance, giving completely his personality to the audience. His action does not coy a cliche, it is not a precise and defined action that takes place only and exclusively in the physical completeness and perfection. It conquests its shape depending on the personality of the Ego that does it, because it is intimate and subjective. For this reason, Education to Theatricality, and the laboratory, in an experience that everyone can live, even if we talk about disability or diversity.

\subsection{Interdisciplinary}

Education to Theatricality is a science that includes different of disciplines such as pedagogy, sociology, human sciences, psychology and the performing arts in general. The scientific basis of this discipline allows us to apply it in all possible contexts possible and with any individual, because it keep the man as he is in the center of its pedagogical process. One of the fundamental principles of Education to Theatricality is the construction of the actor-person; the main aim is the development of creativity and imagination through a scientific training leads by the actor on himself.

This science does not want to transform a man into an actor-object, molding him to product shows that are prepared just to be sold, but to enhance his individual qualities respecting his personality. The final product plays a role linked to the training process of every man, giving a different value to every different personality.

Fundamental to the definition of identity and to the development of imagination and creativity is the conservation of the skill of expression, which represents the starting point, the key element for comparison with each other.

\subsection{Difference}

When we talk about difference and above all about disability we have to wonder what are the characteristics of a human being that make him unique. Being something important to someone else, be in relationship with, have a relationship with someone, can definitely restore dignity to the person. But, before that, the essence of man consists in perceiving their own individuality and identity. He must be perceived by himself as the undisputed leader of his gestures and its actions, who can make the choices and changes. He should be a creator of reality and, above all, the unique artist of his own life. The Education to Theatricality promotes a process of awareness of the Ego, discovering the body and its expressive potentialities. We can imagine that our body is a factory of information which are coordinated and modulated by the Ego. It can be said that the body exists because the Ego exists. The Ego exists because it synthesizes and unify the bodily activity.

And when there is a disability? We can say that we have overcome the old physiological and psychological conception of the body as a given structure, regulated by its own laws, and the Ego as something totally independent from the body but that creates a relation with it and uses it to express. So we realize that all those definitions about a disable body cannot exist anymore. A man must be able to act, to create, to define, to put himself on the line to construct his own real identity. He must be able to be creative. Creativity and imagination are a sort of intermediate space where there are no models, there are no deficit or impairments: man as human being is 
creative.

\subsection{The Creative Subject}

Education to Theatricality is trying to define into strictly scientific terms the process that leads to the development of a creative act. The creative subject is, in fact, object of an interdisciplinary debate: on the one hand, psychologists and neuroscientists are trying to identify the individual characteristics and the mental processes that determine the development of creativity, on the other hand becomes always stronger the reflection on these issues in artistic and expressive field and in pedagogy, too.

Creative man is, in truth, a category of contemporary thought, defined in the second half of the twentieth century. In theater, on horseback nineteenth and twentieth century, with the directors-pedagogues, the concept of creative actor started to be developed and we can speak about the actor as a man who knowingly uses himself to express.

Only from the cultural revolution founded on the figure of Jerzy Grotowski in 1960 and with the development of concepts of art as a vehicle and performer it begins to talk about creative man by nature that uses art, or better arts and expressive language, as a vehicle to consciously work on himself. Beyond the distinction between of artistic genres, Grotowski redefines the idea of art as a field of research about the essence of human existence. Creativity, therefore, ceases to be a matter solely for the artists or for the genius and becomes a characteristic of every human person; this idea is also supported by neuroscience for which each person has a creative potential to develop.

Art is a great opportunity to develop this potential. Precisely for this reason, Education to Theatricality focuses on the creative subject: the theater workshop becomes a method of work based not only on the intention to transmit knowledge, but, above all, on to lead every subject to form himself through a practical experience. Through sensory stimuli, through the movement, the subject experiences in practice (learning by doing) and learns or enhances both cognitive and conative factors that modulate the expression of creativity. The first are determined by the ability to develop different answers to the same situation-question (lateral thinking) or in the ability to consider a problem from different points of view (the mental flexibility); the latter are determined in the development of certain personality traits such as openness to new experiences, willingness to run the risk of making a mistake, attitude to the fascination for the unknown, ability to withstand dominant currents of thought and love for creative activity.

\subsection{Creative Act and Creative Movement}

Talk about creative action in the field of expressive means also introduce the concept of “creative movement”. Creativity becomes action linked, firstly, to the body and the movement.

The creative movement is the development of continuous creative acts, one after the other in time and space, which leads to a simple but fundamental anthropological concept: the relationship between human being and movement. A man is always on the move, immobility is quite impossible. The movement is a specific element of life and plays a central role in relationship with the Ego and with others.

Movement does not arise only from a material need or by an act of will, and it is not just linked to the human musculo-skeletal system: it is also emotion. For this reason, creative movement is connected to the relationship of a subject with the world of creation through the expressive arts and to an analysis of human being and his life, that weaves connections between man and body, between body and expression, between movement-body and creativity. The discipline focuses on the discover of the body in its totality and on the preparation of this instrument as a means of expression. It is important, in fact, not only become aware of the various joints of the human structure and of their use in the creation of rhythmic, gestural and spatial patterns, but also of the inner mood and the attitude in relation to action.

Education to Theatricality, in the study of the creative act and in its realization in the "creative movement", can be considered a science that determines its practice starting from a precise conception of man and his existence. In particular, it is connected to Delsarte's conception about man as an indissoluble unity of three distinct elements-body, soul and intellect-which are interdependent and always in close relationship.

It is interesting to note that, regardless of a specific philosophic conception, theories of this science show a sort of independent efficiency: Education to Theatricality takes into account and verify physiological and neurological processes that govern the sphere of the human body. In fact, this Science, has collected the theatrical 
practice of directors-pedagogues and has made their axioms systematic, drawing from them a universal knowledge.

Creativity, as the ability to transform, build and produce, can be realized in the creative act, that is in an action to which underlies the development of a specific process and a specific state of being. Creativity refers to a productive activity, however, is not only linked to originality (the invention of new ideas or expressions), but also to the reworking of existing elements. The subject, through creativity, transforms the stimuli from outside composing them in a new, unique and personal way; in a study about this issue we can read that: "The creative act [...] is always caused by the encounter between a stimulus coming from the outside and a proper state of consciousness. Through creativity, the subject face in a personal way the inputs of the environment and adapts himself modifying them according to his needs. Creativity requires a constructive way of facing reality and the skill to accommodate experience to be able to break the patterns influencing reality. Create means be able to product something, it is an activity that can produce something out of nothing, but also [...] it means to be able to elaborate elements that already exist in a new original way, to confer to them the character of novelty and uniqueness; with the creativity, the various experiences collected year after year are retrieved into memory, combined and used in a way consistent with the situation” (Oliva, 1998: p. 29).

In the field of expression, creative act is outlined as an action which involves the totality of the human being. To obtain a creative act all elements of the "trinity of the person" are stimulated and used: the intellect in its dimension of mind (fantasy and imagination); the soul in its dimension of emotion and feeling; the body in its dimension of gesture and movement, identity and shape.

Here is the chart that summarizes the theory of the creative act: Figure 2.

Starting from Grotowski's research, Education to Theatricality, as we can read in the diagram above, has defined the creative process as a correlated set of a series of elements:

1) the physical exercise as a starting point (the body of the performative act); 2) the development of it to determine a detailed structure; 3 ) this elaboration processing is determined, furthermore, inside a precise rhythm that governs the action developing it in time and space; 4) the necessary presence of a memory, that is a precise emotional condition. As scientists and neuroscientists affirm, there cannot be creativity without a connection to emotional affair. It can be seen that in the memory, in the physical exercise and in the logical structure of the creative act are involved respectively, the soul, the body and the intellect of the person.

\subsection{Creative Act and Personal Growth}

The complexity, the richness and the globality transform the creative act into a fundamental point of any expression path related to artistic languages; so more if that activity can be used to create educational or training programs. Cesare Scurati defines the laboratory as that place where "you can tackle new routes of exploration, [that allow you] to implement new methods of interaction [...] based on the quality of supervision, of support and of reciprocity, and where it is enhanced the productivity of each one” (Salati, Zappa, 2011: p. 2) so the creative act becomes necessary and indispensable. Without the improvement of personal production we cannot build a real process of growth and development of the person, but without putting at stake the whole person we can obtain not even the development of a creative act. The deepest experience that a person-actor can live is, therefore, the

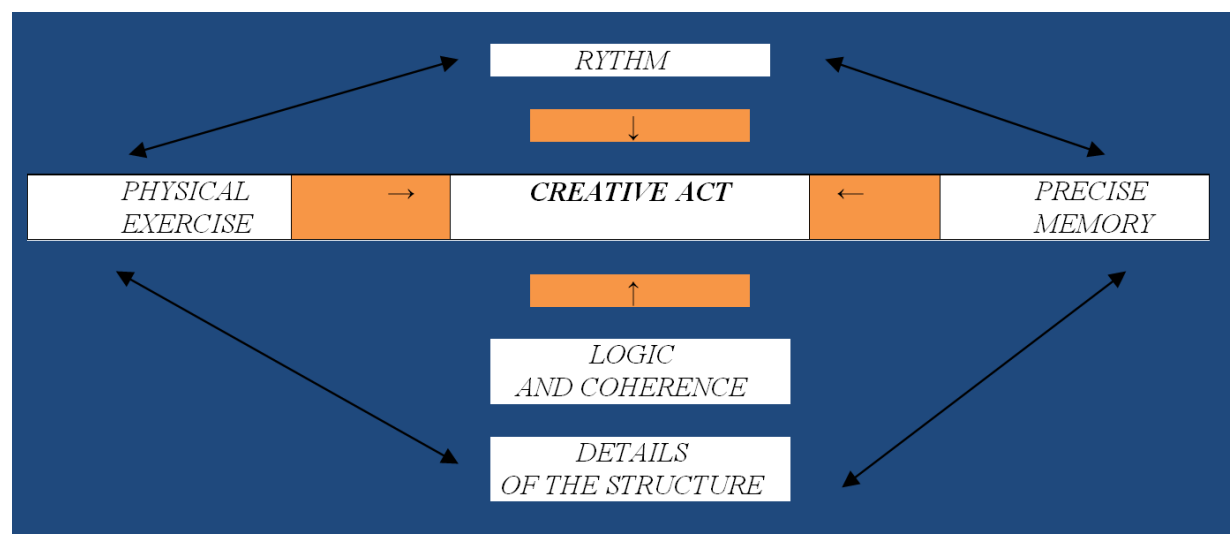

Figure 2. Creative act. Source: Oliva, 2005: p. 310. 
production of a creative act. It encompasses, therefore, the synthesis and the apex of the cultural theatrical and pedagogical revolution that has involved the twentieth century: the perception that the Man has of himself as the heart of the question, capable to change the nature and the events, able to live social changes, subject and protagonist of his life.

\section{The Theatre Laboratory as Educative Methodology}

The theatre laboratory becomes a place of artistic research par excellence: "the word itself reveals the nature of the process. It is not a kind of theater as we can usually think, but rather an institution devoted to research in the field of theatrical art and in particular of actorial work. The performances of the Theatre Laboratorium constitute a kind of operating model in which they are put into practice all the researches carried out in this field. In theater world, this is known as the Grotowski's method. [...] There is a tight contact with many different disciplines such as psychology, phonology, cultural anthropology, and so on” (Grotowski, 1970: p. 11).

Moreover, Education to Theatricality uses only this instrument to help man to educate himself. The process, described and schematized in the previous section, is carried out within the laboratory opening the door to the development of individual creativity. Concretely, this process is divided into two parallel paths: one focusing on the discovery of Ego, discovering personal skills trough a physical and emotional work. The second one aims to the realization of the Ego, through a constructive dialogue with the other. So we have two corresponding technical phases: the monologue and the dialogue. In the phase of monologue we have: "Concentration, observation, breathing, communication, fantasy, imagination and improvisation, then we have the voice, the body, the memory" (Oliva, 1999: p. 93); in the second phase, that of dialogue, there are "sharing space, contact, learning to listen and communicate, the voice, body, the rhythm and the understanding between persons" (Oliva, 1999: p. 93). In general, "the theater workshop seeks to influence three dimensions of the human being: the physic one, the creative one and social one" (Oliva, 2005: p. 236). Even the setting acquires a great importance: the laboratory is a place and a space separated from everyday life in order to facilitate a temporary suspension of routine to allow a more accurate exploration and construction of Ego. So it is possible to build a deeper interaction both at the individual level and group level.

In particular, there are three levels on which is based the whole process. There is a first individual level, in which the person-actor gets in touch with himself through the phase of the monologue; the skills used in this monologue must be projected in everyday life, in order to obtain a greater gratification. Then there is a relational level, in which instead is experienced the phase of dialogue, that is the relationship between the different person-actors; "To try to establish an emotional contact with the partner, it is necessary to develop some others human faculties, such as the accuracy and control of the Ego” (Oliva, 2005: p. 236). Finally, there is a group level, wherein the person-actor experiences within the group.

This process requires a fundamental figure: the conductor of the laboratory. He is certainly a person-actor, but must acquire a more important skill more: "He must be an educator-actor, searching with this word to interweave two fundamental dimensions: the theatrical competence that stimulates the artistic abilities of the students and on the other hand, the specific pedagogical skills of an educator” (Oliva, 2005: p. 237).

His task is not to explicit everything, but provide stimulation and directions which are then interpreted and completed by the student. It can be said that the conductor assumes the role of facilitator, it is not limited to transmit knowledge, but it helps and supports the process of learning.

The theater workshop, as the theater itself, is essentially action, or more precisely construction. This concept can be explained starting from the etymology or the Italian word "formazione" that refers to the idea of model something in such a way to make it assume the desired shape; everything is based on the action of construct and create to something specific. This action embodies "the idea of a form, in the sense as a special way to express themselves with words, writings or with any other artistic activity, as a way of being, living and behaving." (Oliva, 2005: p. 237).

In general, the word "form" refers to a static association, but actually one form is reached only through a series of specific movements. Getting in shape means live a certain process that is summed up in this precise form. For this reason, the terms "form" and "action" are unified, to bring up the idea of something that is created in the moment of action; the motion given by the action, however, embodies a value that is given by the form. To demonstrate this idea, we can submit an example of a real experience of a student during his training workshop: "I always thought that the best way to express a certain feeling was using a non-verbal language, in particular 
dance. So, in case of sadness, for example, I believed that it was enough play a music that stirred me out of sadness and dance, making sure that my body, molding with the rhythm of music, was completely free to move in space; How else I could communicate a state of mind, except through a movement of my body without any constraints? However, I felt that this was not enough: it lacked a piece to complete the puzzle and I did not understand which one. When I attend the lessons of Teatri d'Animazione at the university and Laboratory of Creative Movement, I finally understood which was the problem.

While the music was playing and my body was following it, in fact I was not communicating anything, I was just venting something. The expression of the feeling was not clear because my body was left in the lurch, in fact the subject of the mood was the music and not the body anymore. Carried freely on the music, I lost the original intent (that is communicate a mood) and therefore also the very meaning of what I was doing. There was no dialogue between my intellectual and my corporeal being. Thanks to the laboratory I have understood exactly what I said: I am at the same time body, soul and mind and I can not think that one of this dimension can exist without the others. To give intentionality to my action, then, I have to put my body in close communication with my mind: my movement must be created by intentional forms"1.

The theater workshop, as a process of attribution of meanings, can connect the action with thought and vice versa. For this reason, while giving ample space on the physicality and action, it not neglects the essential moment of reflection; this allows acquiring a greater awareness of what has been accomplished. The reflection, such as promotion of the comparison, is designed as a central element because it allows revising the process through the sharing of commonalities and differences of the experience. The aim of the conceptualization of the experience is to allow a greater understanding and help people to seek shared meanings. This is our idea of training.

One can understand, therefore, the importance of this educational idea through the Theater Workshop: it is based on verbal and non-verbal exercises having as objective a more intense conscious and interpersonal relationship. Furthermore, the fact that everything takes place within a group (which must be small to make a good job) encourages socialization, very important for education. Through it, every individual discovers himself. But there is another objective promoted by the Theater Laboratory: the development of creativity. Inside the lab, in fact, everybody can express their specificities and diversity: each one has a message to communicate through his body and his voice, which allows him to find his identity and to accept others as a person who has something to say; reciprocity becomes the place where manifest meanings, which are the simply result of the creative process led forward by each.

Through the movement of our body, creativity becomes action and thus leads the actor-person to realize a creative act. Inserted in this described process, the performer has the chance to experiment, to dialogue and to listen to himself, but always in new ways; so he is forced to seek new ways and to go beyond his own beliefs, arriving to create actions and movements imbued of creativity, because he becomes the one that creates something new. In other words, "the actor-person [...] is the master of his own creativity, which originated by a great inner strength, is the bearer of authentic values in which the spectator can see himself" (Oliva, 2005: p. 231).

\section{The Role of Theatre Educator}

Modern life requires a rapid adaptability by man. The flexibility is not only required in the workplace, but it's part of everyday life in the studio, in sports, in family, approaching to new scientific and technological discoveries. It is necessary then, in particular for professional educators, help the learners-that can be children, youth or adults-to build a good awareness of itself, a provision to interpersonal relationship. Education is the science of change since it is the finality of education. A change which is not only a modification of the conditions of subject's life, but first and foremost as a transformation of the perception of himself. The task of the educator is to provide the resources and situations more suited to the change. Onorina Gardella says something more: "The educational work to change something is always relational. It always presupposes two or more subjects, two people in their entirety. It need a comparison or a conflict with the other” (Gardella, 2007: p. 34). And Luigi Diotti says: "Education is not made just by aims, content, methods and means, because in practice it is the concretization of a relationship between two people and it is influenced by the structure of their life” (Dotti, 2006: p. 87).

The conductor of a theater laboratory has the opportunity to influence the relations and the organization of the

${ }^{1}$ Testimony of a student of the Course of Teatri d'Animazione, Faculty of Education, Catholic University of Milan (Italy). 
group through the construction of the setting of work and the care of its dynamics. He has the main function to hold together the entire group and help each person to take an active part in the theatrical action. The director educator has to be able to activate a context of play and to promote a positive affective climate. Every member of the group should have trust in the operator before to have it in himself. An atmosphere of actual trust will permit to the group members to feel safe enough to express themselves. Only when the student will have the certainty of not be judged he may invest part of himself in creative work. Salvo Pitruzzella says: "Come into play" implies an investment of psychic energy which is offered to the other, in the form of collaboration, of trust, of capacity to take risks; moreover there is the need for everyone to own a proper communication space, that should be recognized by the other one. The educator must be the guarantor of this balance, but at the same time can not be an external controller: on the contrary he is a participant of the process, being aware of his emotional and imaginative investments" (Pitruzzella, 2009: p. 21).

Flexibility, adaptability and elasticity are qualities that the conductor must necessarily possess in such a way to be able to adapt his educational proposals to the environment and to the people he works with. He must be able to translate questions, convey messages and calibrate requests, in relation to the age of the students and the characteristics of the group. If the educator understand which are the factors that inhibit creativity, he will be able to help the student to understand and overcome them. Gardella suggests: "In this sense, the educator is also a counselor because it supports the subject towards the discovery of the personal identity. He cannot bind to precise patterns this self-discovery, he has to suggest new ways, see goals, recognize and propose from time to time the possible choices, the opportunities, the new aims, the real opportunities” (Gardella, 2007: p. 55).

The theatrical educator, through his function as director, is able to trigger a creative process. Theater becomes an instrument, a sort of physical and mental space in which you can share a fantasy. One of the tasks of the educator, in particular of the theatrical educator, is the contribution to a harmonious growth of the Ego. Helping a person to become aware of his own body means help him to discover himself and to make better use of his personal resources. The educator, in fact, offer resources that should be not just consumed, but reworked by the subjects in a new energy (Triani, 2002: p. 29). He asks not only to do, but especially to think about what you are doing. The conductor of the laboratory must activate efficient situations in the theater simulation from an educational point of view. To make sure that the personal creative skills can be developed by education, he has to offer adequate tools and contents. Therefore it is essential to prepare an educational theatrical plan with specific and prefixed goals.

\section{The Planning Activity in Relation to Expressive Arts}

Planning activity is a peculiar action of the educator, in fact he has to be able to give sense to actions, through a continued openness to a creative life and to its possibilities. He should not think in a standardized way, but has to create a vision that aims at the human being's personality, considering, at the same time, his relationships, his social and cultural context.

This is because "the planning activity does not require you to work only to achieve something, but also to work on something” (Santerini \& Triani, 2007: p. 64). Planning activity allows you to avoid the risk to make trivial and superficial the educational relationship and the professional work of the educator, whose specificity is precisely to be an agent of human development, that is individual and collective.

Once you understand the importance of planning in the educational world, you have to answer to another question: how to plan? And through what tools?

It is essential that each educator tries to answer to these questions when he has to face a group of people. There are so many theories in educational field that it is really useful and necessary to understand which one to choose to plan reasonable activities that aim at achieving specific objectives. One way may be to choose education through expressive arts, that is, an education that prefers artistic expression to develop knowledge, awareness and discovery.

Any art presupposes creation, preparation, research, experimentation, evaluation, as well as to be ready to put yourself on the line. It is clear that to do that the artist must possess precise skills, otherwise, if everything was left to a free improvisation, would decay the deepest sense of his actions. This is meeting point between art and education; in fact education is considered an art, too. Pedagogy assumes the same actions, the same projects, the same research of sense of art; and this also can not be improvised.

"Creating a work of art, a man stretches out towards the achievement of that form of the Ego that is already 
inside himself. His goal is to reach it. As well as the work of art also the process through which the subject is forming emanates from the desire to reach the actual form of the Ego. Every man aspires to a perfect and authentic existence, despite the difficulties” (Musaio, 2007: p. 239).

The artist as well as the educator seems to live a paradigmatic experience because, even with all its intentionality and will, he cannot not reach fully the beauty of things that surround him: the artist tries to reach and approach to the inmost reality of things and people, through his works and the relationship of love that takes over in the implementation phase. The educator tries to reach the most intimate Ego of individual through the action and the educational relationship.

"Education is an experience permeated by the component of risk, but that never ceases to attract because of the beauty of human implications. Education can be seen as a fact, an act and an event from the contours not always well distinguishable, especially if you pay attention to the challenge of the postmodern culture that project educational subjects in a context that seems to have lost the references to help people to develop an authentic relationship with himself and reality" (Musaio, 2007: p. 12).

In addition, every educator, while still aiming at a deep knowledge of every person, will never reach a level of total understanding. For this reason he has to puts into play all the instruments he owns, using not only the reason, but also the intuition, which focuses precisely on the immensity of the human being. It is this kind of reason that opens the door to wonder and to discovery. An educator to work and to create works of art, has to use those tools of expression. If it is true that art is a vehicle, we can affirm that it is a powerful and effective mean that opens up the doors to an education which aims at the innermost part of Ego; "Maritain has defined a creative intuition, "as a dark grasping his own personality and the things in a knowledge through the union or through the connaturality that arises in the spiritual unconscious and becomes fertile only in action" (Musaio, 2007: p. 25).

To this first characteristic that unites art and pedagogy, we can immediately adds another: both these "worlds", in fact, want to animate life. This means give blood, give shape to daily lives, giving sense, to rediscover their routine under a new light, to live their relationship through different dynamics. The soul is the most inner part of the Ego, the most hidden and silent, but, at the same time, even the most noisy, that "shouts" inside, that shakes us. The soul is the "storm" that shakes, that haunts, it is energy; it is the most irrational and emotional aspect of man: "[The word 'anima'] brings us back to the Greek word Anemos, which means wind, or blow. There is a wind that blows out of us that can be as light as the breeze or shocking as a hurricane; and there is also, using metaphorical language, the wind, the spirit, that, according to various religious traditions, was 'breathed' into us. A dynamism that work without being 'grabbed', which you can hear and feel, but not see” (Iori, 2012: p. 13).

This helps to confirm that "projecting life to pursuit beauty can emerge as one possible path to search certainty, something to grab to not disperse in a fortuitous combination of events and variables” (Musaio, 2007: p. 27).

Through its symbolic language, art has always helped the individual to approach the meaning of life and to reach that level of knowledge that man can only perceive because it does not occur in his eyes as matter; in other words it helps man to find his voice.

This is a very difficult moment for the contemporary man, because it is characterized by a new search for values, by a crisis at quite every level of life, by an education permeated by uncertainty and doubt, it is absolutely necessary an intervention to re-evaluate the situation, that restores its value, through a watchful eye on the finality and tools needed to reach it. The bigger investment of every educator is giving blood; in fact, the contemporary crisis that man is experiencing is the bearer of discomfort and negativity, it can also be seen as an opportunity, a stimulus, a challenge to renew the human existence in all its profiles. "In times of difficulty we must have the courage to invest in educating, because it is the point to start again” (Iori, 2012: p. 10). If it is true that "education is based on a planning activity that should make full and beautiful the existential experience, even in adverse or difficult conditions of crisis" (Iori, 2012: p. 10), then it is its duty to accept the complexity with realism in order to stimulate its authenticity without falling into resignation.

In this context, the proposal carried out by artistic and expressive languages is perfectly embedded. Its most important characteristic is to be able to mobilize the most intimate resources and potentialities of the person, in order to allow a training experience that forces a continuous dialogue with every element: body, soul and intellect. These languages require a regular exchange between theory and practice: planning activity with expressive arts proposes a concrete experience, based on physical actions, because it consider a human being as creative and to create every human being need to practice, in the true sense of the word. But to give sense to a plan, the use of these languages must rely on a concrete theoretical basis. Without this ongoing relationship, the planning activity (as well as education) would not have sense. There can not be one without the other; doing does makes 
sense if it is not accompanied by a reflection and by awareness, and viceversa.

What has been said hitherto may seem obvious, but it is not: in contemporary days, when it is tacitly affirmed the idea that rationality rules on the most sensitive and creative part of the human being, we can not stop and try to find into the most pure expressive part of us (left on the sidelines and maybe forgotten) the answers to try to propose an education guided by values and certainties.

Bringing to light this most intimate aspect of man, the artistic methodology is presented as a pedagogical tool based on the co-construction of activities which "aims to enhance the vitality, the expression of people, the interests of groups, of organizations, through a series of expressive, cultural, recreational interventions, based on a logic of participation" (Iori, 2012: p. 15), if fact its aim is helping people to find a meaning of life. For this reason, the educator who want to plan following this idea must also assume the role of "animatore": to be an "animatore" means promote actions directed to the soul of people, so we talk about "anim-a-zione". Through this type of training activity, an educator, focusing on the soul of the people, should work on the sensitivity, expressiveness, intersubjectivity and imagination, which are the fundamental dimensions of man. Its goal is to pull out "the artist" that is inside every human being and promote the wandering side of each one. A human being who wanders, looks, travels and simply makes mistakes to find himself.

This training allows you to express your Ego and to give voice to what appears silent; in addition, an experiential perspective is supported because it want to teach to do following proper ideas and dreams. This is the look of someone who is ready to welcome and enhance every movement/action: "we do not want to define stylistic-executive models, but to build pathways able to reflect the thought and the emotion of the body" (Iori, 2012: p. 107). The body is a just another feature of expressive arts: in fact, they propose a model of education in which the body participates fully because a human being can not exist without it. Unfortunately, there is the risk to consider the human being without considering body, because it is dominated by the intellectual/rational component. But in this way a human being is not considered in his totality and in his fullness, that instead is promoted by the artistic-expressive vision: "it favors the use and exploration of the body in order to experience new and different ways of feeling and being, for access to emotions which are nested in the body, and so they are difficult to represent using language, and to transform them into new gestures that accompany the change and the development of skills" (Iori, 2012: p. 109). This is crucial because the human being needs to narrate and narrate about himself. Expressive arts, especially theater and dance (if we talk about creative movement), favor: "the discovery of dramaturgic body, that is a body able to tell small stories and emotions through its experiences [...]. [This] is important [...] especially for the improvement of the capacity of relationship with the Ego and with the others. It is important even for the relationship with cognitive intelligence (a dramaturgic body brings self-enclosed his history, it is a sort of body-chest that contains physicality and emotions, it is the body that communicates, even without the use of verbal language)" (Iori, 2012: p. 124).

In conclusion, this reflection provides a starting point for responding positively to the question that was asked initially: "Why a planning activity through expressive arts?".

Because they offer the opportunity to not follow models to human being, but to be a model of himself. Through the proper tools of art, every man can tell everything about himself, without excluding any existential component, allowing him to considered himself the protagonist of his action. This is true at any age, regardless of sex and culture: the art is part of human life and the creativity, which is present in every person, can be cultivated thanks to the tools of expression that art itself offers.

Then, getting in touch with himself and putting himself in discussion to find himself again, a human being can create deeper relationships with others, and this is an opportunity for social integration, which is not limited to a superficial level, but, on the contrary, has its roots into a truer and deeper level, because he made a process to give a new meaning to life.

Thus, "the identity of any person enter into a relationship through a narrator reality; action, speech and gesture become instruments to investigate life" (Iori, 2012: p. 144).

\section{A Project}

\subsection{Introduction}

Everyone knows that adolescence is a stage of life that requires special attention because it represents the age in which the human subject makes the choice to build his Ego and his identity, in order to consolidate their ideals. To achieve this goal, the teenager is looking for meaning and value to accept; in other words, it is with adoles- 
cence that begins the process of acceptance of Ego that will accompany every man throughout his life cycle. Precisely for this reason we can see in the adolescent an attitude of challenge that led him to enter continuously in conflict with the other, especially with the adults, in which he sees an obstacle; the adult, in fact, represents for him a person who wants to tell him how to build his identity. That creates the attitude of provocation that usually occurs through the transgression of the rules that the adult imposes.

At the same time, the adolescent face another process: pubertal development. Transformation of body is a sign of growth but, at the same time, can be experienced as a crisis because these changes can not be well accepted. The shapes and the voice change: we must accept another form of ourselves. This event represents a moment of adolescent crisis which contributes to the research of the Ego, which is not only moral and ideal, but also linked to the body.

In this sensitive period, it is extremely useful that teenagers receive many stimuli to help them to understand the different aspects of reality, and to discover their resources and their limits. Furthermore, it is essential that they will relate with adults able to give satisfactory answers, without the claim to decide for them what to do, but simply able to offer an educational proposal that would give a meaning of life. In particular it is useful that this educational need is upheld and carried out within the Secondary School, since these students are inserted in a path that will lead to the training of their personal identity and everything they face is a continuous discovery. It is important to promote in school prevention through educational tools aiming at the development of creative skills, abilities present in every human.

An efficient tool to stimulate the expression of personal creativity, of self-discovery and of interaction cooperative with others is the theatrical experience, more precisely the theatre laboratory, conceived in relation to the real needs, interests and skills of teenagers. The laboratory is in fact a vehicle through which they can search and discover their own identity (that is linked not only to the body), not only at the individual level, but also at the group level.

Then, teachers have to active participate, working with the Educator to Theatricality.

\subsection{Recipients}

The students of the Secondary School.

\subsection{Finally}

Encourage the psycho-physical and social wellness of the teenager in relation to its age through the theatrical culture and, in particular, through the laboratory.

\subsection{Objectives}

Discovery and development of creative potentialities and of socialization; enhancement of imagination and mimicry expression; self-awareness; expression through the gesture, the voice, the colors, the sound, the storytelling, the movement.

\subsection{Contents}

- Non-verbal language: creative movement:

-Awareness of the body and its expressive possibilities (breathing, coordination and dissociation, balance, contraction and relaxation, theatrical space, equilibrium of the stage, Greek choir, etc.).

-Education and control of voice and muscles.

-Verbal and non-verbal communication.

-Individual and collective improvisation with and without music.

-Composition of sequences in the group.

-Use of space in each dimension.

-Telling a story with your body.

-History, action-process, composition.

-Construction and use of the neutral mask.

- Verbal language: the theatrical reading:

-Technique of voice and phonetic rules. 
-Breathing exercises for the proper use of the diaphragm.

-Labial gymnastics and vocal exercises for good articulation.

-Phonetic rules.

-Exercises of modulation of the voice.

-Use of physiological resonators.

-Colours of words.

- The space: handling of material and creativity:

-The space of representation and the stage space.

-Space: Movement and performance space.

-The use of different scenic materials and articles.

-The handling of the materials.

-Planning and construction of sets and costumes.

-The relationship between music and the scene.

-Detection of sounds and noises and sound effects creation.

- The play:

-The text: reading, analysis and interpretation.

-The relationship between dramatic text and narrative text.

-The specificity of the play: exercises.

-Analysis of some plays.

-The dramaturgical model.

\subsection{The Method}

Every appointment should be fun and educational ad every teenager will be available to work with different techniques and materials to stimulate his fantasy. Each topic will be introduced by explicit references to the History of Theater. The moments of this route are articulated to experiment verbal and non-verbal languages, in particular through the use of the "story-telling". Laboratory is a safe environment, without any judgment, which allows the participants to release their feelings and emotions, procured through the experience of dramatic narrative the gratifications they need and to meet other personalities in a fun and deep collaboration.

Story-telling is very important for every human being. Furthermore, even hear the stories of others is important: these stories are mirrors in which each individual sees aspects of himself. Often, however, this information remains at an unconsciousness level, to which a boy can access only in specific situations, for example, during the theater laboratory, where the student is stimulated to create and tell stories.

At the end of each appointment there is a moment of feedback, that is dedicated to the verbalization. This promotes the externalization of opinions and experiences favoring a critical observation of the experience and improving the ability of sharing thoughts in a context that does not wants to be judgmental and in which are taken into consideration the activities and not the personal elements of each subject; it will be accomplished by using age-appropriate tools and considering the ability of recipients.

The plan consider the process experienced by every teenager the most important phase of the laboratory, and it will lead to the construction of a creative project (a performance), which will be the visible result of the whole process.

\subsection{The Check}

There are some intermediate and final check which are useful to orient the work, through a series of individual and collective tests. They are useful to evaluate what changes have occurred in each student and in the relationship between the members of the group according to the offered stimuli, to the contents of the course and understanding the degree of interest of every different modules. Therefore, this check should be realized by the theatricality educator who leads the laboratory; he will tend to widen the check in collaboration with teachers who are participating in the activity.

There are:

- Identification by the theatricality of the educator of sensitive teachers who can accept to plan activities in collaboration;

- Planning moments of verbalization to allow an exchange between the participants about the activities carried 
out, the degree of understanding and experiences related to the proposed stimuli;

- Motivate the operational proposals and their goal for help students to achieve a level of self-assessment;

- Assume some moments when the spectators can become part of the scene, such as answering or being called into question;

- Educators and teachers should give just a superficial information about the content and the development of thematic regarding the performance they will see to be allowed to understand the final product;

- Prepare illustrated flash card that synthesize the experience to prepare an exhibition as introduction to the final performance.

\subsection{Organization}

The duration of the laboratory is 20 - 25 hours per class.

Each appointment lasts about 2 hours.

\section{Conclusion}

At the end of this work, in reference to the chance to find a new way of education, we have tracked down and discovered a new road illuminated by expressive arts. When you understand how the reference to beauty is inherent in human being, and how he needs to translate, explain and show himself through the artistic language, we understand that art can be a privileged way to discover a meaning of life. Art therefore has transcended the mere definition of product with which for too long has been linked, to be considered in a totally different logic: a logic focuses on the process, that allows every human to discover himself, in relation to his Ego and to others.

This has been confirmed by the specific and concrete project, result of a reflection that invoked the educational action of planning in reference to the expressive arts. Expressive arts can be considered as innovative tools to support the human being in his endless existential quest. If we consider them a vehicle, we can say that they represent the preferred way to reach the inner Ego of the human and give breath to everything that otherwise would remain intimately silent. Art offers the great privilege of understanding the human being in his totality and uniqueness, because it reflects the unity of its essential elements (which are body, soul and intellect). It can be stated that in art and thanks to art, man can manifest itself fully and truthfully. Moreover, thanks to the innovative work made by some great figures of the Twentieth century like Jerzy Grotowski, we know that there is a primary need to focus on our body and that is necessary to "listen" to it to fully consider their own experience.

Without an awareness of the corporeal being, in fact, the man would be incomplete and would never be able to reach the meaning of his existence.

Through this work, moreover, it is possible to conceive an education that goes beyond the simple everyday life, to rediscover it under a new aspect thanks to art, which allows users to review their daily actions giving a deeper meaning. In particular, it has been demonstrated how a theatre laboratory, offers a training course that allows persons to rediscover their Ego. This is necessary for every human being because it allows him to put himself on the line, to build more solid convictions; it is a journey that leads him to get lost, but only to find himself stronger, with a deeper awareness about his personality, his relationship with others and with the surrounding environment. This process develops in the person a profounder consciousness of his limitations and his potentialities combined with a more conscious creative feeling.

Since every man is part of a continuous movement (from a physical and existential point of view), it seems essential to propose an experience that will bring every man to fully enjoy the creative fluidity in which he is naturally inserted, and we can name it creative movement.

Refer and deepen this perspective is really important in the field of education, because it leads the human being to come into contact with his Ego and with the others, sharing everything: body, soul and intellect. If you share the most intimate part of yourself with the other you can create a constructive and educative dialogue. This is the actual challenge of an educator, who wants to plan using expressive arts: achieving the intimacy of the person to extract its deeper skills, but above all, to ensure that everything can be constructed through an individual path made of sharing.

Expressive arts become a real chance to face the discomfort and the contemporary crisis that the world of education is experiencing. Choosing this way, the educator invests fully on his role and his profession, because he accompanies the person towards himself and to his personal fulfillment, he is a guide to realize a plan of life 
according to a higher value: the human relationships.

\section{References}

Dotti, L. (2006). Storie di Vita in Scena. Il Teatro di Improvvisazione al Servizio del Singolo, del Gruppo, della Comunità. Torino: ANANKE.

Gardella, O. (2007). L'Educatore Professionale. Finalità, Metodologia, Deontologia. Milano: Franco Angeli.

Grotowski, J. (1970). Per un teatro povero. Roma: Bulzoni.

Guatterini, M. (2008). L’ABC della danza. La storia, le tecniche, i capolavori, i grandi coreografi della scena moderna e contemporanea. Milano: Mondadori.

Iori, V., Arioli, A. A., Bruzzone, A., Carosio, D., Casadio, E., Chiappini, I., Crescini, C., Dallari, S., Di Pietro, M., Dosi, A., Formenti, M., Frare, L., Gianotti, P., Guzzoni, F., Iori, A., Mapelli, V., Musi, M., Nicolussi Perego, E., Oliva, L., Stramaglia, G., Triani, M., \& Zagatti, F. P., (Eds.) (2012). Animare l'educazione. Gioco pittura musica danza teatro cinema parole. Milano: Franco Angeli.

Musaio, M. (2007). Pedagogia del bello, suggestioni e percorsi educativi. Milano: Franco Angeli.

Oliva, G. (1998). Il teatro nella scuola. Milano: LED.

Oliva, G. (1999). Il laboratorio teatrale. Milano: LED.

Oliva, G. (2005). Educazione alla teatralità e formazione. Dai fondamenti del movimento creativo alla form-a-zione. Milano: LED.

Payne, H. (1997). Danzaterapia e movimento creativo. Trento: Erickson.

Pitruzzella, S. (2009). Manuale di Teatro Creativo. 200 Tecniche Drammatiche da utilizzare in Terapia, Educazione e teatro Sociale. Milano: Franco Angeli.

Salati, E. M., \& Zappa, C. (2011). La pedagogia della maschera. Educazione alla Teatralità nella scuola. Arona: Editore XY.IT.

Santerini, M., \& Triani, P. (2007). Pedagogia sociale per educatori. Milano: Educatt.

Testa, A. (2005). Storia della danza e del balletto. Roma: Gremese Editore.

Triani, P. (2002). Sulle Tracce del Metodo. Educatore Professionale e Cultura Metodologica. Milano: I.S.U. Università Cattolica. 
Scientific Research Publishing (SCIRP) is one of the largest Open Access journal publishers. It is currently publishing more than 200 open access, online, peer-reviewed journals covering a wide range of academic disciplines. SCIRP serves the worldwide academic communities and contributes to the progress and application of science with its publication.

Other selected journals from SCIRP are listed as below. Submit your manuscript to us via either submit@scirp.org or Online Submission Portal.
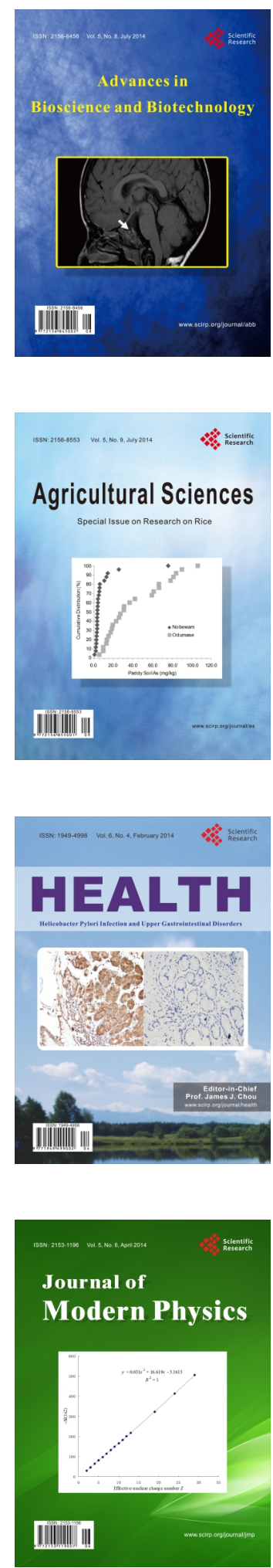
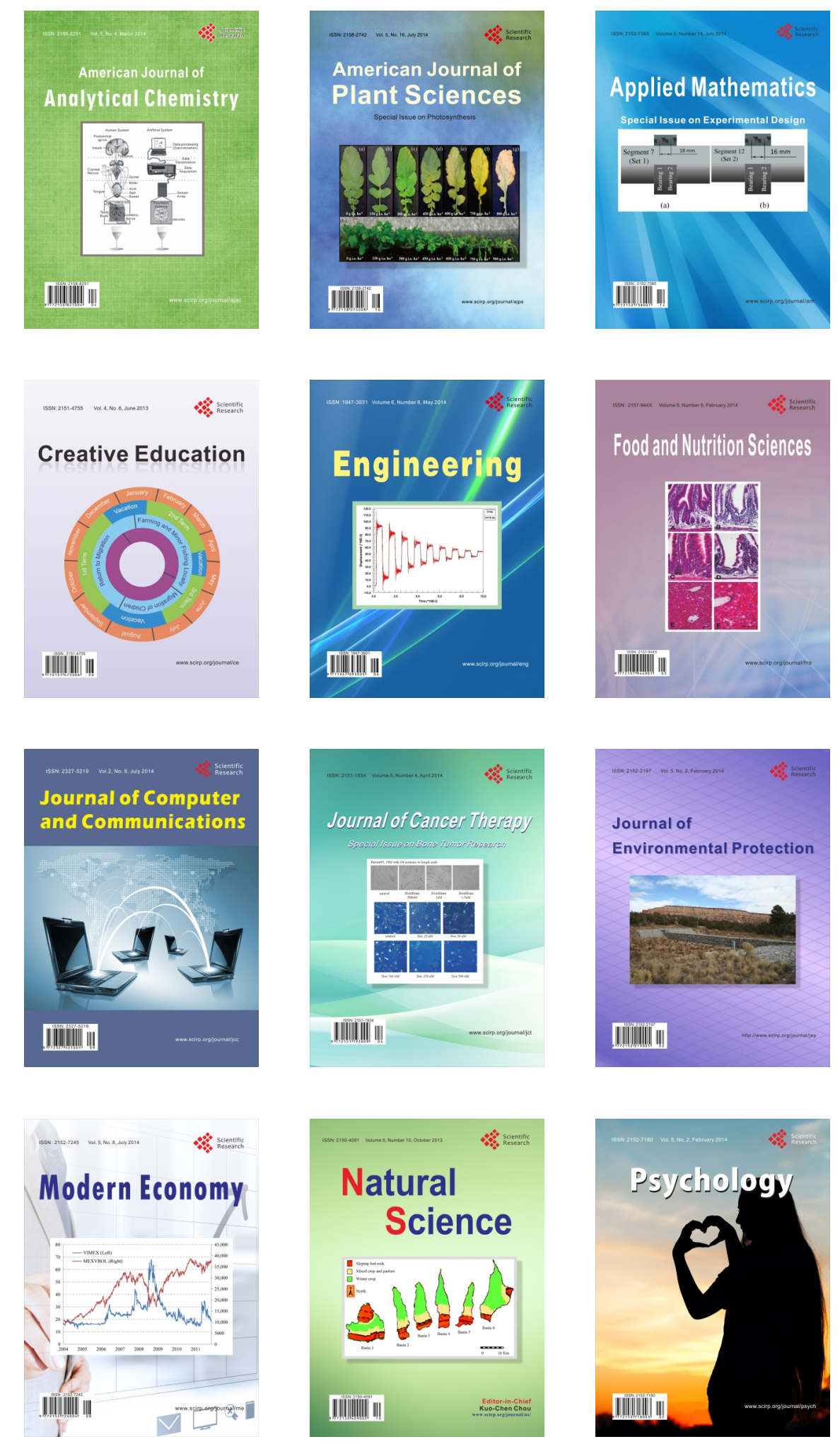